\title{
Analisis Pengaruh Variasi Komposisi Katalis Pada Proses Pack Carburizing Baja Karbon Rendah Terhadap Nilai Kekerasan dan Struktur Mikro
}

\author{
Lega Putri Utami, Budi Istana,Adi Indra \\ Program Studi Teknik Mesin Fakultas Teknik \\ Universitas Muhammadiyah Riau Pekanbaru \\ Email: \\ legaputri@umri.ac.id \\ budiistana@umri \\ Adi.indra930@gmail.com
}

\begin{abstract}
Abstrak
Pentingnya pemilihan material yang tepat sesuai kebutuhan industri dapat memperpanjang usia pakai material dan dapat meminimalkan cost maintenance untuk penggantian material. Didalam industri air minum dalam kemasan, memiliki mesin-mesin yang tidak lepas kaitannya dengan material, baik yang terbuat dari nilon maupun logam, material tersebut di aplikasikan sesuai dengan fungsinya. Terdapat komponen mesin yang mengalami keausan pada sebuah industri air minum dalam kemasan, keausan terjadi pada shaft gearbox conveyor yang terbuat dari baja ST41 dan mengalami keausan antara bagian spi dan lobang spi. Jenis keausan yang terjadi pada shaft gearbox conveyor ini adalah keausan (surface fatigue wear) yang terjadi karena interaksi permukaan, dimana bagian permukaan mengalami gesekan beban berulang secara terus menerus. Adapun tujuan dari penelitian ini adalah mengetahui pengaruh persentase katalis BaCO3 terhadap nilai kekerasan dan struktur mikro pada proses pack carburizing baja ST41.
\end{abstract}

Kata Kunci: Pack Carburizing, Baja ST41, Keausan, Heat treatment.

\begin{abstract}
The importance of choosing suitable material as industrial need to lengthen the use of material and minimize cost maintenance. In water mineral industrial, there are some machines that made of nylon or metal. Those materials are applied based on their functions. There are some machines components which scraped in water mineral industrial. It can be happened in shaft gearbox conveyor that made of steel ST41 which is scraped between spi and hole spi. The type of scrape is surface fatigue wear that happened because of surface interaction which is friction continually. The aim of this research is to know the effect of catalyst percentage BaC03 toward strange value and micro structure on pack carburizing process at steel ST41.

\section{PENDAHULUAN}

Material logam merupakan bagian yang tidak terpisahkan dari proses pemesinan dalam dunia industri. Seperti besi cor, besi baja, dan stainless. pentingnya pemilihan material yang tepat sesuai kebutuhan industri dapat memperpanjang usia pakai material dan dapat meminimalkan cost maintenance untuk penggantian material. Didalam industri air minum dalam kemasan, memiliki mesin-mesin yang tidak lepas kaitannya dengan material, baik yang terbuat dari nilon maupun logam, material tersebut di aplikasikan sesuai dengan

fungsinya. besi baja karbon biasanya di aplikasikan untuk shaft gearbox conveyor, conveyor roller, besi siku dudukan ducting, dll. Material-material tersebut memiliki usia pakai baik karena gesekan yang di dapat secara terus menerus sehingga menyebabkan keausan maupun korosi. Komponen lain yang mengalami keausan pada industri air minum dalam kemasan ini terjadi pada shaft gearbox conveyor. Shaft gearbox conveyor ini terbuat dari baja St41 dan mengalami keausan antara bagian spi dan lobang spi. Jenis keausan yang terjadi pada shaft gearbox conveyor ini adalah keausan (surface fatigue wear) yang terjadi
\end{abstract}


karena interaksi permukaan, dimana bagian permukaan mengalami gesekan beban berulang secara terus menerus. Dari masalah yang teradi pada shaft gearbox conveyor tersebut, saya tertarik untuk mengangkat nya menjadi judul tugas akhir, dengan memberi perlakuan permukaan dan perlakuan panas pada material shaft gearbox conveyor tersebut dengan metode pack carburizing agar tingkat kekerasan pada permukaan shaft gearbox tersebut dapat meningkat.

\section{METODE}

Bahan untuk spesimen uji adalah baja karbon rendah ST41 dengan komposisi kimia di tunjukan pada tabel berikut:

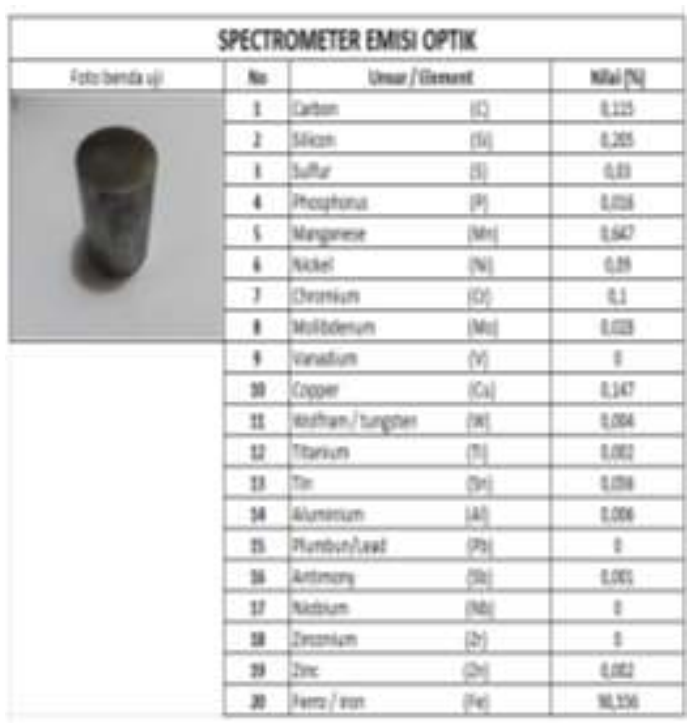

Tabel 1. Hasil Uji Komposisi kimia Material

Metodepenelitian

yang

$\mathrm{di}$

gunakandalampenelitianiniadalaheksperimenta

1.Hal

inidilakukanuntukmengetahuipengaruhpack

carburizingpadabaja st41

denganvariasipersentase

$\mathrm{BaCo} 3$

menggunakankarbonaktif.

\begin{tabular}{|c|c|c|c|c|c|}
\hline \multirow{2}{*}{ No } & \multirow{2}{*}{ Spesinen Uf. } & \multicolumn{3}{|c|}{ Jenis Pergujan } & \multirow{2}{*}{ Total } \\
\hline & & Specto & SEI & Kekersan & \\
\hline 1 & Raw Uterial & 1 & & 1 & 1 \\
\hline 2 & Galis:R\% & & 1 & 1 & 1 \\
\hline 3 & Katals $2 \%$ & & 1 & 1 & 1 \\
\hline 4 & Galis 308 & & 1 & 1 & 1 \\
\hline 5 & katlis 48 & & 1 & 1 & 1 \\
\hline \multicolumn{5}{|c|}{ Total Syesinea Lfi } & 5 \\
\hline
\end{tabular}

Tabel 2 : Variable penelitian

Spesimen uji dimasukan ke dalam kotak baja dan diisi media karburasi dengan komposisi katalis berfariasi yaitu 10\%, 20\%, $30 \%$, dan $40 \%$. Kotak karburasi kemudian di tutup rapat dan dimasukan ke dalam dapur pemanas (electric furnace) dipanaska sampai temperatur $900^{\circ} \mathrm{C}$ dan di tahan pada suhu tersebut selama 30 menit. Kemudian spesimen dikeluarkan dari kotak baja dan didinginkan menggunakan air. Material yang telah di karburizing dilakukan uji SEM dan kekerasan, untuk uji Sem terdapat 4 spesimen dan untuk uji kekerasan terdapat 5 spesimen, dimana untuk uji kekerasan setiap spesimen dilakukan di 3 titik berbeda.

\section{HASIL DAN PEMBAHASAN}

\subsection{Pengujian Kekerasan Menggunakan Hardnes Vickers Portabe}

Hasil uji kekerasan menggunakan hardnes vickers prtable dengan 5 spesimen uji di 3 titik berbeda. Dan disusun dalam bentuk dabel dan grafik berikut :

\begin{tabular}{|c|c|c|c|c|c|c|}
\hline \multirow{2}{*}{10} & \multirow{2}{*}{ lanossikiktitls } & \multicolumn{3}{|c|}{ TtatPesgijan } & \multirow{2}{*}{ 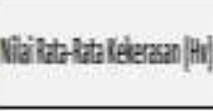 } & \multirow{2}{*}{ Soler } \\
\hline & & Thit & Tith2 & This & & \\
\hline 1 & PawNateial & EHH & $\mathrm{WH}$ & 19H & BH & 122 \\
\hline 2 & Bribalis & 3245 & sthin & $42 \mathrm{H}$ & 450 & 6 \\
\hline 3 & Zholats & $\mathrm{WH}_{\mathrm{H}}$ & $32 H$ & 通H & 314 & 5,5 \\
\hline ? & 3 istetals & 334 & 3ith & $35 \mathrm{H}$ & $326 \mathrm{H}$ & 47 \\
\hline 5 & Whitals & 355 & 3ath & $32 \mathrm{Hi}$ & $376 \mathrm{fH}$ & 77 \\
\hline
\end{tabular}

Tabel 3 : tabel hasil pengujian kekerasan baja st 41 . 
Grafik 1 : Grafik Hasil pengujian kekerasan baja ST41.

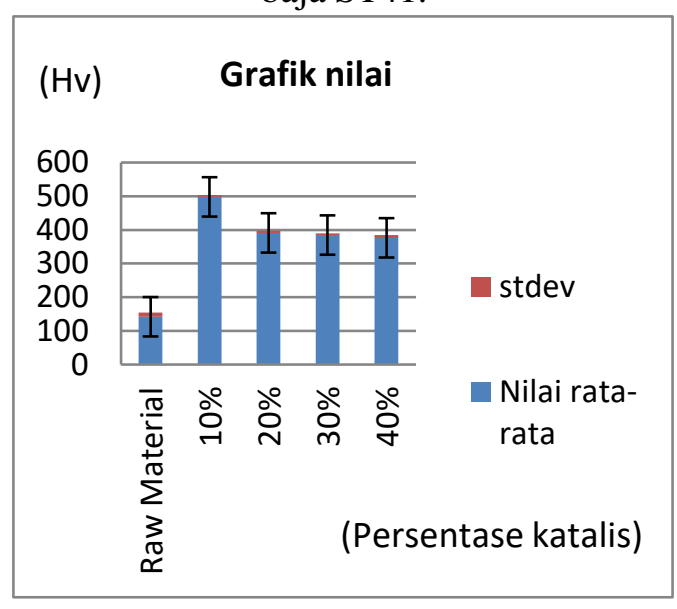

Dari hasil pengujian kekerasan maka didapatlah hasil berupa tabeldata kekerasan dan grafik di atas, dimana nilai kekerasan tertinggi setelah dilakukannnya proses karburizing pada baja St41 terdapat pada campuran komposisi katalis $10 \%$ dengan nilai kekerasan 498 Hv. Campuran komposisi katalis $10 \%$ dapat meningkatkan nilai kekerasan baja ST41 sebesar 250,7 \% dari nilai kekerasan raw material. Tingginya nilai kekerasan pada komposisi katalis $10 \%$ disebabkan oleh perbandingan volume antara karbon dan katalis di dalam kotak karburizing. Kotak karburizing hanya dapat di isi dengan volume 450gram. Komposisi katalis $10 \%$ hanya mengandung volume karbon sebesar 405 gram, Komposisi katalis 20\% mengandung volume karbon sebesar 360 gram, komposisi katalis $30 \%$ mengandung volume karbon sebesar 315 gram, dan komposisi katalis $40 \%$ mengandung volume karbon sebesar 270 gram. Semakin tingginya nilai komposisi katalis akan mengurangi nilai kekerasan material. Karena katalis hanya berfungsi untuk mempercepat laju difusi atom ke dalam baja, dan karbon berfungsi untuk meningkatkan nilai kekerasan pada material.

\subsection{Hasil Pengujian SEM (Scaning Electron Microscope)}

Pada pengujian ini spesimen yang di uji berjumlah 4 buah yaitu terdiri dari baja ST41 yang telah di karburizing dengan variasi komposisi 10\%, 20\%, 30\% dan 40\%. Sehingga menghasilkan gambar struktur mikro sebagai berikut:

\subsubsection{Foto Hasil Struktur Mikro Baja} ST41 Dengan Komposisi Katalis 10\%

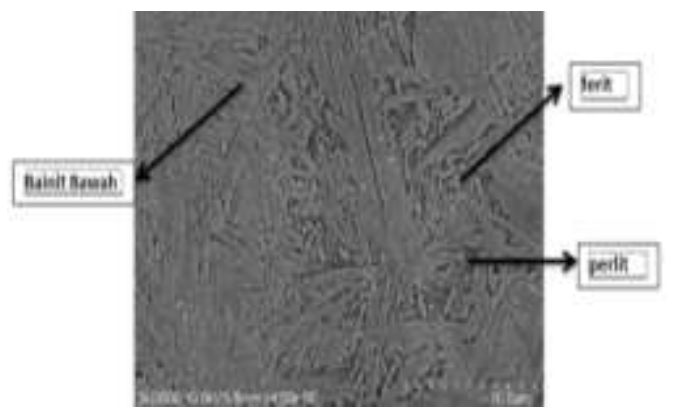

Gambar 1 : Foto Hasil Struktur Mikro Baja ST41 Dengan Komposisi Katalis 10\%

Struktur mikro dalam baja tergantung pada kadar karbon di dalamnya, karbon merupakan suatu ikatan interstitial dalam besi dan membentuk suatu larutan padat,.pada Gambar 4.1 terlihat fasa bainit lebih dominan dari pada fasa ferit dan perlit. bainit dihasilkan dari reaksi eutectoid non lamellar, sedangkan perlit terbentuk akibat campuran fasa ferit dan cementit (Fe3C). Bainit bawah (Lower Bainit) terbentuk pada temperatur $250-350^{\circ} \mathrm{C}$. Terbentuknya Bainit bawah disebebkan karena suhu pembentukan nya yang rendah, dan memiliki komposisi katalis yang rendah 
sehingga laju difusi atom ke dalam baja juga lambat.

\subsubsection{Foto Hasil Struktur Mikro Baja} ST41 Dengan Komposisi Katalis 20\%

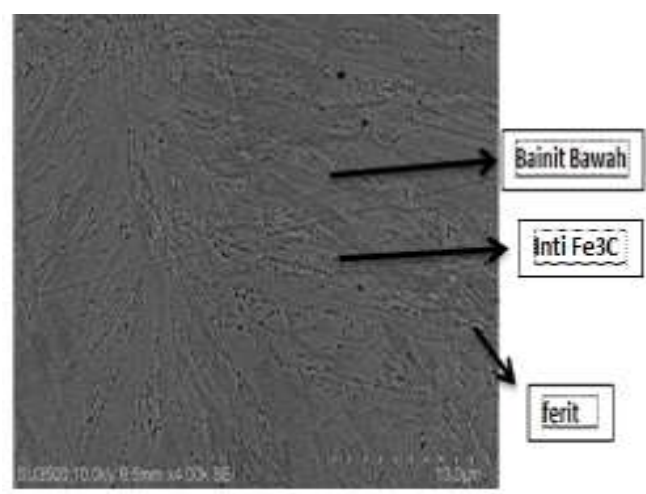

Gambar 2 : Foto Hasil Struktur Mikro Baja ST41 Dengan Komposisi Katalis 20\%

Pada hasil struktur mikro Baja ST41 dengan komposisi katalis 20\% fasa bainit lebih dominan terlihat. Pada hasil SEM ini juga terlihat bintik-bintik hitam yang merupakan inti $\mathrm{Fe} 3 \mathrm{C}$. Inti $\mathrm{Fe} 3 \mathrm{C}$ akan membentuk perlit apabila bercampur dengan fasa ferit. Skema pembentukan lamellar perlit akan terjadi apabila inti $\mathrm{Fe} 3 \mathrm{c}$ terbentuk lempengan dan tumbuh bersama ferit $(\alpha)$ yang pengintiannya dimulai dari batas butirnya. Belum terbentuknya fasa perlit pada campuran katalis $20 \%$ ini menyebabkan perbandingan nilai kekerasan yang berbeda dengan komposisi katalis $10 \%$. Penurunan nilai kekerasan campuran katalis $10 \%$ ke campuran katalis $20 \%$ adalah $27,3 \%$

\subsubsection{Foto Hasil Struktur Mikro Baja} ST41 Dengan Komposisi Katalis 30\%

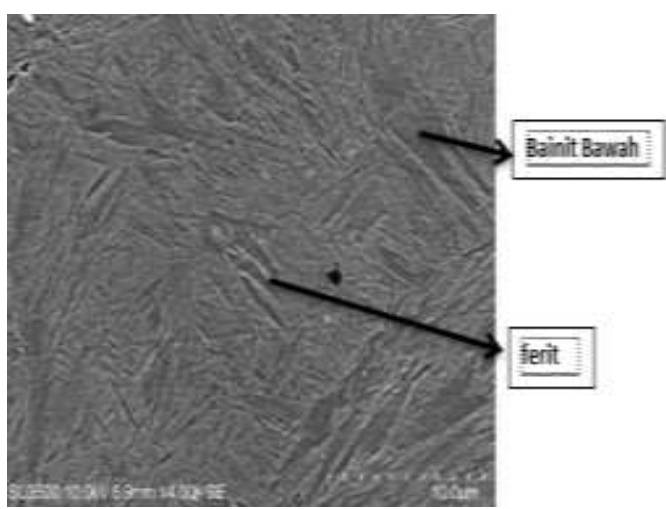

Gambar 3 : Foto Hasil Struktur Mikro Baja ST41 Dengan Komposisi Katalis 30\%.

Pada hasil SEM baja ST41 dengan komposisi katalis 30\% terdapat 2 fasa yaiu bainit dan ferit. Pada hasil SEM ini fasa bainit terlihat lebih dominan.

\subsubsection{Foto Hasil Struktur Mikro Baja} ST41 Dengan Komposisi Katalis $40 \%$

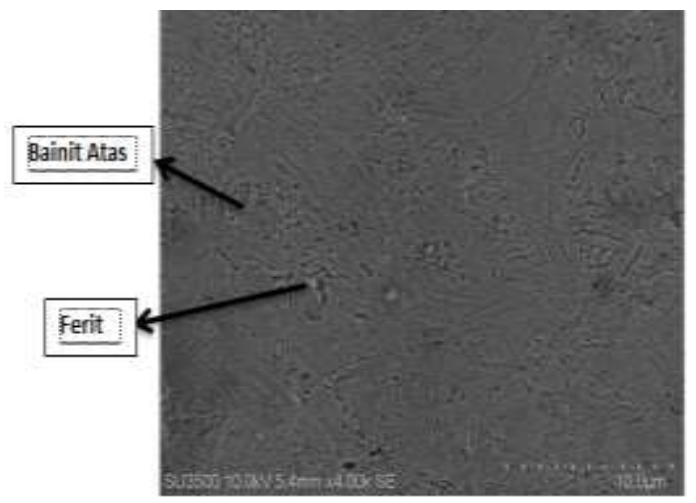

Gambar 4 : Foto Hasil Struktur Mikro Baja ST41 Dengan Komposisi Katalis 40\%

Pada komposisi katalis $40 \%$ terjadi perbedaan fasa, dimana bainit atas lebih dominan dari fasa ferit, timbulnya fasa bainit atas di sebabkan oleh laju difusi atom yang masuk ke dalam baja. Perbedaan antara bainit atas dan bainit bawah di dasarkan pada karbida yang terdistribusi di antara daerah ferit. Laju difusi karbon selama pembentukan banit bawah sangat lambat, sehingga atom-atom tidak dapat bergerak cukup cepat untuk 
menghindari terjebaknya di dalam pertumbuhan ferit, sementara pada komposisi katalis $40 \%$ laju difusi atom sangat cepat karena tingginya persentase Katalis, laju difusi atom inilah yang menyebabkkan terbentuknya fasa bainit atas.

\section{SIMPULAN}

Spesimen uji baja karbon St41 yang diberi perlakuan karburizing dengan komposisi katalis $10 \%$ dapat menaikan nilai kekerasan hingga $250,7 \%$ dari nilai kekerasan raw material. Penambahan katalis 20\%, 30\%, dan $40 \%$ tidak memberikan pengaruh yang signifikan terhadap nilai kekerasan baja St41 karena katalis hanya berfungsi untuk mempercepat laju difusi atom ke dalam baja. Dengan semakin bertambahnya persentase katalis di dalam kotak karburizing hanya akan mengurangi volume karbon di dalam kotak karburizing.

Fasa bainit terlihat lebih dominan pada bagian permukaan baja karbon St41 yang telah di karburizing dengan variasi katalis 10\% 20\% 30\% dan 40\%. Pada komposisi katalis $10 \%$ terdapat fasa perlit, dimana fasa perlit tersebut terbentuk karena campuran antara fasa ferit dan sementit. Campuran antara kedua fasa inilah yang menyebabkan kenaikan yang signifikan pada campuran katalis $10 \%$.

\section{DAFTAR PUSTAKA}

Anonim. 2015. Penomoran Baja StrukturalMenurut DIN 17100. http://teknikmesinmanufaktur.blogsp ot.co.id/2015/02/Penomoran-bajastruktural-culture,June 2003

Darmanto. 2006 . Pengaruh Holding Time Terhadap Sifat Kekerasan Dengan Refining The Core Pada Proses Carburizing Material Baja Karbon Rendah. http://jurnal.unimus.ac.id/index.php/j $\underline{\mathrm{tm} / \text { article/view/595/647 }}$

Djafrie 1983. Metalurgi Mekanik, Terjemahan dari Mechanical Metallurgy, Erlangga Jakarta.

Djaprie, S., 1983, Ilmu dan Teknologi Bahan. Erlangga, Jakrta.

Eko, J.A., 2006.Pengaruh Media Karburasi dan Bahan Kimia Aktif Terhadap Kekerasan Cangkul, skripsi S1 teknik mesin FT,UNS, Surakarta.

Faqih Hidayatulloh. 2005. Pengaru Ketebalan Media Karburasi Pada Proses Pack Carburizing Terhadap Nilai Kekerasan Baja Karbon Rendah Ditelusuri 3 Desember 2017.

https://divpenhmtmulm.files.wordpre ss.com/2017/01/faqih-h-h1f113201.

Jensen dan Chenoweth. 1992, Kekuatan Bahan Terapan. Erlangga. Jakarta.

Lathkin, Y. 1965. Enginering Physical Metallurgy, Foreign Languange Publishing House. Moscow.

Malau, V. 1999 Pengetahuan Bahan Teknik dan Manufaktur. Universitas Sanata Dharma, Diktat Bahan S1;p 17. Yogyakarta

Masyrukan, 2006. Penelitian Sifat Fisis Dan Mekanis Baja Karbon Rendah Akibat Pengaruh Proses pengorbanan Dari Arang Kayu Jati. Universitas Muhammadiyah Surakarta.

Muhammad Iqbal. Pengaruh Temperatur Terhadap Sifat Mekanis Pada Proses 
Pengkarbonan Padat Baja Karbon Rendah. Ditelusuri 4 Desember 2017.

https://media.neliti.com/media/public ations/221797-pengaruh-temperaturterhadap-sifat-mekan.pdf

Muhammad Sadat Hamzah. Peningkatan Ketahanan Aus Baja Karbon Rendah Dengan Metode Carburizing. Ditelusuri 4 Desember 2017.

https://media.neliti.com/media/public ations/222254-peningkatanketahanan-aus-baja-karbon-re.pdf

Shackelford James, 1996. Introduction to materials Science for Engineers, Fourth edition, Prentice Hall International Inc.

Schonmetz A. Dan Gruber K. 1994.

Pengetahuan Bahan dalam

Pengerjaan Logam (Alih Bahasa :

Dip-Ing. Eddy D
Murdani, A. Nurcahyat.Viyus, Sujatmiko, A. 2012 Modul Ajar PraktekUjiBahanTeknik, PoliteknikNegri Malang: Malang

Murtiono Arief. Pengaruh Quenching Dan Tempering Terhadap Kekerasan dan Kekuatan Tarik Serta struktur Mikro Baja Karbon Sedaang Untuk Mata Pisau pemanen sawit. Ditelusuri 3 Desember 2017.

http://jurnal.usus.ac.id/index.php/edinamis/arti cle/download/2635/1334.

\section{Hardjapamekas).Bandung:} Penerbit Angkasa.

Yudiono, H. 2005, Metalurgi Fisik. Diktat. Semarang: Jurusan Teknik Mesin. UNWAHAS. 